УДК 81'23:159.9.07(045)

DOI https://doi.org/10.26661/2414-1135-2021-84-9

\title{
ПРИНЦИПИ УКЛАДАННЯ АНКЕТИ ДЛЯ ВІЛЬНОГО АСОЦАТИВНОГО ЕКСПЕРИМЕНТУ
}

\author{
Грищук Ю. В. \\ кандидат педагогічних наук, старший науковий співробітник \\ Київський національний лінгвістичний університет \\ вул. Велика Васильківська, 73, Київ, Украӥна \\ orcid.org/0000-0002-5306-0301 \\ yuliia.hryshchuk@knlu.edu.ua
}

\author{
Ключові слова: вільна \\ асоиіачія, психолінгвістичне \\ дослідження, резилентність, \\ слова-стимули, мовна \\ свідомість.
}

У статті обгрунтовано доцільність проведення вільного асоціативного експерименту в межах реалізації прикладного проєкту «Корпусно-експериментальна діагностика резилентності представників різних лінгвокультур та розробка поведінкових моделей їх адаптації до кризових явищ» (номер державної реєстрації: 0121U107493), що виконується в Київському національному лінгвістичному університеті. Охарактеризовано процедуру проєктування анкети з урахуванням принципових положень психолінгвістичних досліджень. Укладання анкети для вільного асоціативного експерименту розглянуто як ітераційний процес, що складається з таких основних етапів: 1) визначення мети проведення анкетування, яка співвідноситься з метою вільного асоціативного експерименту; 2) формування списку слів-стимулів; 3) визначення форми проведення експерименту (усна, усно-письмова, письмова, електронна) і способу представлення стимульного матеріалу; 4) проєктування анкети; 5) оформлення анкети; 6) тестування (перевірка) й оптимізація анкети. Встановлено, що у разі проведення анкетування за допомогою онлайн-сервісу Google Forms важливо врахувати обов'язковий складник вільного асоціативного експерименту - спонтанність реакції. Для цього необхідно виключити можливість вносити зміни у заповнену анкету та контролювати часовий параметр (обмежити час заповнення анкети та/або вказувати на спонтанність реагування). Зроблено висновок, що для досягнення мети вільного асоціативного експерименту укладання анкети повинно відповідати таким ключовим принципам: цілепокладання; реалізації дизайну анкети, орієнтованого на респондентів; етичним принципам. Основні етичні норми та принципи проведення вільного асоціативного експерименту передбачають: надання респондентами усвідомленої згоди про участь в анкетуванні та на статистичну обробку їхніх персональних даних; ознайомлення респондентів з інструкцією проведення анкетування, прогнозованим часом його перебігу, метою та організаторами анкетування; гарантування респондентам конфіденційності та безпеки; анкетування серед неповнолітніх проводиться за згодою їхніх батьків або офіційних опікунів. 


\title{
PRINCIPLES OF QUESTIONNAIRE DESIGN FOR FREE ASSOCIATIVE EXPERIMENT
}

\author{
Hryshchuk Yu. V. \\ Candidate of Pedagogical Sciences, Senior Researcher \\ Kyiv National Linguistic University \\ Velyka Vasylkivska str., 73, Kyiv, Ukraine \\ orcid.org/0000-0002-5306-0301 \\ yuliia.hryshchuk@knlu.edu.ua
}

Key words: free association, psycholinguistic research, resilience, stimulus words, linguistic consciousness.
The article substantiates the expediency of conducting a free associative experiment within the implementation of an applied project "Corpus and Experimental Diagnostics of Resilience of Different Language Cultures Representatives and Behavioural Models Development for Adaptation to Crisis Phenomena". The project is being implemented at the Kyiv National Linguistic University. The procedure of questionnaire design taking into account the basic provisions of psycholinguistic research is described. Questionnaire design for free associative experiment is considered as an iterative process. This process consists of the following main stages: 1) determination of the purpose of the questionnaire, which is correlated with the purpose of a free associative experiment; 2) formation of the list of stimulus words; 3 ) determination of the form of the experiment (oral, orally and written, written, electronic) and the method of presenting stimulus material; 4) designing a questionnaire; 5) questionnaire design; 6) testing (verification) and optimization of the questionnaire. It has been established that in the case of conducting a survey using the online service Google Forms, it is important to take into account the mandatory component of a free associative experiment - spontaneity of reaction. It is necessary to exclude the possibility to make changes to the completed questionnaire and to control the time parameter (limit the time of filling in the questionnaire and / or indicate the spontaneity of the response). It is concluded that in order to achieve the goal of a free associative experiment, the questionnaire must comply with the following key principles: goal setting; implementation of the design of the questionnaire focused on respondents; ethical principles. The basic ethical norms and principles of conducting a free associative experiment include: providing by respondents informed consent to participate in the survey and the statistical processing of their personal data; acquaintance of respondents with the instructions of the survey, the estimated time of its course, the purpose and organizers of the survey; guaranteeing confidentiality and security to respondents; questionnaires among minors are conducted with the consent of their parents or official guardians.
Постановка проблеми. Практика використання асоціативного експерименту як методу, спрямованого на виявлення асоціацій, що склалися в індивіда в його попередньому досвіді [2, с. 53], грунтується на концепції вільних асоціацій у психоаналізі, яка стрімко розвивалась у межах досліджень у галузі когнітивної психології, нейробіології і нейропсихоаналізі (L. Bellak, A. Kehyayan, K. Best, J.-B. Schmeing, N. Axmacher, H. Kessler, T. Rabeyron, C. Massicotte, J. Hopkins). Сьогодні це досить ефективний метод для вивчення мовної свідомості та мовної картини світу, когнітивних, лінгвокультурологічних i психолінгвістичних проблем [2, с. 55], а також для вирішення певних завдань в соціології, культурології, політології та інших соціальних і поведінкових науках.

«Вільна асоціація» передбачає свободу від будь-яких детермінант, окрім інтрапсихічних [12]. Як зазначає Й. Гопкінс, вільні асоціації дозволяють суб'єкту представити свій інтрапсихічний світ через посилення уваги до внутрішнього досвіду та її зменшення до навколишнього середовища. Це сприяє дослідженню інтрапсихічної реальності як генератора своєрідної віртуальної дійсності, оскільки вільні асоціації допускають виникнення прихованого змісту, пов'язаного 3 важливими елементами психічного життя суб'єкта [14]. 
Вільна асоціація $\epsilon$ основою для вивчення модальностей та ефектів психічної трансформації. Вона дозволяє інтегрувати та трансформувати внутрішній досвід у межах реальних інтерсуб'єктивних відносин. На думку окремих дослідників (T. Rabeyron, C. Massicotte), первинна форма вільних асоціацій в основному стосується емоцій. Вільні асоціації є взаємопов'язаними з особливою психічною активністю, яка відповідає тому, що В.Р. Біон [13] називає «альфа-функцією» - здатністю перетворювати емоції на усвідомлений зміст. Інтрапсихічна асоціативність зберігає слід навколишнього середовища - «екстерналізовану» асоціативність, з якою зіткнувся суб'єкт [19].

Соціально-психологічні дослідження (Н. Joffe, J. Elsey) показують, що люди можуть значною мірою не усвідомлювати передумови певних уподобань і способів дій. Для установок, стереотипів i самооцінки характерні імліцитні компоненти. Під «імліцитним» розуміється те, що минулий досвід впливає на судження способом, інтроспективно невідомим суб'єктові. Використовуючи метод вільних асоціацій, було виявлено, що стереотипи та забобони, які традиційно вважаються свідомими, мають імліцитний вимір і не обов'язково співвідносяться 3 відповідями, отриманими на прямі питання 3 того чи іншого стереотипного судження [15, p. 173]. На думку О.С. Комар, «стереотипність реакцій індивіда на певне мовне явище визначається насамперед особливостями культури, носієм якої $є$ мовець. <..> будь-яка національно-маркована мовна одиниця є стереотипом ментально-лінгвального комплексу представника певної етнокультури, який реалізується у процесі мислення та спілкування у вигляді нормативної локальної асоціації до стандартної для цієї культури ситуації» [6, с. 60].

3 огляду на вищезазначене в межах реалізації проєкту наукової роботи молодих вчених «Корпусно-експериментальна діагностика резилентності представників різних лінгвокультур та розробка поведінкових моделей їх адаптації до кризових явищ» (номер державної реєстрації: 0121U107493), що виконується в Київському національному лінгвістичному університеті, серед послідовних стадій методологічної процедури діагностики резилентності стереотипів поведінки представників різних лінгвокультур було виокремлено проведення вільного асоціативного експерименту [16].

Оскільки резилентність розглядається у межах різних підходів, серед яких: когнітивного біхевіоризму - вивчення процесів емоційної регуляції поведінкових реакцій людей в кризових, конфліктних ситуаціях [3, с. 75], доцільність проведення вільного асоціативного експерименту підтверджується результатами дослідження ней- ронної активності під час застосування вільних асоціацій з реченнями, пов' язаними 3 конфліктом. Вільні асоціації використовувалися як істинний психодинамічний індикатор того, чи дійсно кожна потенційно пов'язана 3 конфліктом пропозиція зачіпала інтрапсихічний конфлікт [17]. Такий конфлікт розглядають як психодинамічне явище, під час аналізу якого варто враховувати [8]: 1) значення минулого досвіду (психотравм, афектів, вчинків тощо); 2) формування певної поведінки (психологічних захистів, стереотипів). Дослідникам (А. Kehyayan, K. Best, J.-B. Schmeing, N. Axmacher, H. Kessler) вдалося дійти висновку, що теми, пов'язані з конфліктом, у процесі застосування методу вільних асоціацій викликають значно сильніші реакції на поведінковому, фізіологічному та нервовому рівнях у суб'єктів 3 «очевидним конфліктом».

Д.Г. Виговська підкреслює, що асоціативний експеримент дозволяє виявити системність змісту образу свідомості, що стоїть за словом у різних культурах, а також системність всієї мовної свідомості носіїв різних культур, транслюючи тим самим унікальність і неповторність образу світу кожної культури. Отже, мовна свідомість може розглядатися як засіб пізнання чужої культури в іiі предметній, діяльнісній та ментальній формах, а також як засіб пізнання своєї культури. 3 огляду на це саме асоціативні зв'язки є диференціюючими параметрами гендеру, віку, рівня та спрямованості освіти, умов життя і стрес-фактора [1, с. 1158].

Дослідження асоціативного експерименту як методу в психолінгвістиці, проблеми проведення вільного асоціативного експерименту вже отримали достатнє наукове висвітлення. Проте проблема укладання анкети для вільного асоціативного експерименту потребує системного аналізу.

Об'єктом дослідження є процедура укладання анкети для вільного асоціативного експерименту, предметом - принципи укладання анкети для вільного асоціативного експерименту.

Мета статті - назвати і обгрунтувати принципи укладання анкети для вільного асоціативного експерименту.

Відповідно до мети визначено такі завдання: охарактеризувати процедуру проєктування анкети 3 урахуванням принципових положень психолінгвістичних досліджень; описати зміст анкети для вільного асоціативного експерименту в межах реалізації проєкту наукової роботи молодих вчених «Корпусно-експериментальна діагностика резилентності представників різних лінгвокультур та розробка поведінкових моделей їх адаптації до кризових явищ», що виконується в Київському національному лінгвістичному університеті.

Виклад основного матеріалу дослідження. Укладання анкети для вільного асоціативного 
експерименту - це ітераційний процес, що складається $з$ декількох різних етапів. Спираючись на результати дослідження основних проблем проведення вільного асоціативного експерименту, наведені O.I. Горошко [2], було виокремлено такі основні етапи укладання анкети для вільного асоціативного експерименту:

1 етап - визначення мети проведення анкетування, яка співвідноситься 3 метою вільного асоціативного експерименту.

2 етап - формування списку слів-стимулів.

У дослідженні до основних слів-стимулів різних мов було віднесено такі: crisis, pandemic, stress, adventure, opposition / la crise, la pandemie, le stress, la adventure, l'opposition / die Krise, die Pandemie, Stress, das Abenteuer, das Opposition / kryzys, pandemia, stres, przygoda, opozycja / криза, пандемія, стрес, пригода, протистояння та інші, які термінологічно формують науковий об'єм поняття «резилентність» [5].

3 етап - визначення форми проведення експерименту (усна, усно-письмова, письмова, електронна) й способу представлення стимульного матеріалу.

У межах вільного асоціативного експерименту за допомогою онлайн-сервісу Google Forms буде розроблено анкету з набором слів-стимулів (див. вище). Погоджуємося з твердженням Н.О. Стефанової, що «надані відповіді в електронній формі зменшать ризики отримання спотворених асоціативних реакцій на відповідний стимул» [10, с. 354].

4 етап - проєктування анкети.

Під час проєктування анкети варто пам'ятати про необхідність дотримання загальноприйнятої структури [11]: 1) вступна частина (вказується повна інформація, що ідентифікує анкету: тема та мета анкетування; інформація про установу / організацію / науковий колектив, що проводить дослідження; звернення до респондентів; чіткі інструкції щодо заповнення та надсилання анкети; вказівка на анонімність та використання результатів анкетування виключно в наукових й дослідницьких цілях; 2) основна частина (містить слова-стимули); 3) класифікаційна частина, так звана «паспортичка», що складається з блоку запитань, які розкривають особистісні характеристики респондента: соціально-демографічні (стать, вік, місце проживання тощо), освітньо-професійні (рівень освіти, місце і стаж роботи тощо), культурні (національність, етнічна приналежність, рідна мова, мова спілкування, ставлення до релігії та ін.); 4) завершальна частина (містить подяку респондентові за участь в анкетуванні).

На думку О.І. Горошко, деякі чинники (віково-статева приналежність респондента, умови його життя, рівень освіти та інші) роблять сильний вплив як на змістовне наповнення асоціатив- них полів, так і на їх структуру, що пояснюється взаємозв' язком між соціальними та біологічними характеристиками людини та іiї вербальною поведінкою [2, с. 59].

Особливо важливим чинником, що впливає на кінцеві результати асоціативного експерименту, як вважає С. Мартінек, є чинник статі, «оскільки жіночі і чоловічі реакції демонструють суттєві розбіжності не лише у кількісному, але й у якісному складі реакцій відповідно до того, які саме концептуальні структури вони експлікують i наскільки ці структури є психологічно вагомими для респондентів залежно від їхньої статі» [7, c. 27].

У межах дослідження будемо керуватися принципами забезпечення гендерної чутливості (англ. ensure gender-sensitivity): 1) всі дані, які збиратимуться, буде розподілено за статтю; 2) під час підготовки звітної документації окремий розділ буде присвячено оцінці наданих реакцій як чоловіків, так і жінок; 3) буде здійснено аналіз щодо можливих відмінностей у діагностиці резилентності стереотипів поведінки представників різних лінгвокультур залежно від статі респондента.

На результати вільного асоціативного експерименту, окрім іншого, впливає місце проживання респондента, а отже, політичні, соціально-економічні процеси. С. Мартінек зазначає, що не менш важливим чинником $€$ вплив іншої мови під час проведення експерименту. Дослідник наводить такий приклад: «в анкетах $\mathrm{AE} 3$ носіями української мови, результати якого представлені у «Славянском ассоциативном словаре», окремі стимули були подані з російським перекладом: чоловік (муж) i чоловік (мужчина), дружина (жена) і жінка (женщина), - що не могло не позначитися на чистоті експерименту» [7, с. 27].

3 огляду на вищезазначене в анкеті проєкту наукової роботи молодих вчених респондентам буде запропоновано вказати вік, стать, місце проживання, національність, рідну мову, мову, якою переважно спілкується респондент, рівень освіти та професію.

5 етап - оформлення анкети. Формат анкети повинен бути функціональним та візуально привабливим для респондента.

У разі проведення анкетування за допомогою онлайн-сервісу Google Forms важливо врахувати обов'язковий складник вільного асоціативного експерименту - спонтанність реакції. Для цього необхідно: 1) виключити можливість вносити зміни у заповнену анкету. Дослідники зазначають, що під час електронного збору асоціативного матеріалу можуть бути використані два способи: заповнення анкети в мережі Інтернет 3 можливістю повернення до всього списку стимулів і, відповідно, можливістю внести зміни в свої 
асоціації, і варіант, який не дозволяє вносити зміни, що унеможливлює момент рефлексії [9, с. 6]; 2) контролювати часовий параметр (обмежити час заповнення анкети та / або вказувати на спонтанність реагування). На думку O.I. Горошко, асоціативний експеримент можна розглядати як різновид комунікативної ситуації. Якщо співвідносити таку ситуацію з письмовою формою мови, то цю дихотомію можна зіставити $з$ дихотомією «підготовлена мова». Під час письмової форми проведення асоціативного експерименту у респондента більше часу, він працює в зручному для себе темпі. Проте при цьому може зникнути спонтанність реакції. Саме тому потрібно досить жорстко контролювати часовий параметр [2, с. 56].

6 етап - тестування (перевірка) й оптимізація анкети. На фінальному етапі важливо перевірити укладену анкету на предмет іiі змістовності, доступності та зрозумілості інструктивних матеріалів для респондентів. Для цього проводиться пробне анкетування трьох і більше респондентів 3 метою отримання їх рекомендацій щодо вдосконалення анкети. За результатами укладається остаточний варіант анкети.

Для досягнення мети вільного асоціативного експерименту укладання анкети повинно відповідати таким ключовим принципам:

1. Принцип цілепокладання.

Необхідно пам'ятати про цілі проведення анкетування та експерименту загалом. Проблеми, що виникають під час укладання анкет, часто пов'язані з відсутністю чітких аналітичних даних, неврахуванням зворотного зв'язку між цілю, інструментарієм та результатами. Необхідно зосередитися на ключових інформаційних потребах, попередньо підтверджених відповідним планом аналізу [18].

2. Принцип реалізації дизайну анкети, орієнтованого на респондентів.

Анкета повинна мати логічну структуру, чіткі інструкції, ретельні формулювання запитань.

3. Етичні принципи.

Необхідно дотримуватися етичних норм. Основні етичні норми та принципи проведення вільного асоціативного експерименту передбачають $[4 ; 18]$ : усі респонденти надали усвідомлену згоду про участь в анкетуванні та на статистичну обробку їхніх персональних даних; усі респонденти знають мету проведення анкетування, як інформація буде використовуватися, чому вона збирається та ким; усі респонденти ознайомлені 3 інструкцією проведення анкетування, прогнозованим часом його перебігу; усім респондентам гарантується конфіденційність та безпека; анкетування серед неповнолітніх проводиться за згодою їхніх батьків або офіційних опікунів.
Висновки. Вільний асоціативний експеримент трактується як дієвий метод для вивчення мовної свідомості носіїв різних культур, а також когнітивних, лінгвокультурологічних і психолінгвістичних проблем. Укладання анкети для вільного асоціативного експерименту - це ітераційний процес, що складається 3 декількох етапів: 1) визначення мети проведення анкетування, яка співвідноситься 3 метою вільного асоціативного експерименту; 2) формування списку слів-стимулів; 3) визначення форми проведення експерименту (усна, усно-письмова, письмова, електронна) і способу представлення стимульного матеріалу; 4) проєктування анкети; 5) оформлення анкети; 6) тестування (перевірка) й оптимізація анкети. Досягнення мети вільного асоціативного експерименту супроводжується дотриманням таких основних принципів під час укладання анкети: цілепокладання; реалізації дизайну анкети, орієнтованого на респондентів; етичних принципів.

Перспективи подальших досліджень вбачаємо в опрацюванні наданих асоціативних реакцій респондентів на слова-стимули (криза, конфлікт, пандемія, протистояння, стрес) за допомогою комп'ютерного інформаційно-аналітичного сервicy STIMULUS.

\section{ЛІТЕРАТУРА}

1. Выговская Д.Г. Ассоциативный эксперимент как один из методов в психолингвистике. Наука ЮУрГУ : материалы 66-й научной конференции. Секции социально-гуманитарных наук. 2014. С. 1157-1164.

2. Горошко Е.И. Проблемы проведения свободного ассоциативного эксперимента. Известия ВГПУ. 2005. № 3. С. 53-61.

3. Грищук Ю.В. Дискурсивні маркери резилентності особистості як прояви іiі адаптації до кризових явищ. «Ad orbem per linguas. До світу через мови». Матеріали Міжнародної науково-практичної відеоконференції «Світ цінностей і цінності у світі», 13-14 травня 2021 року. Київ : Видавничий центр КНЛУ, 2021. C. 75-77.

4. Загородня О. Веб-проєкт «СТИМУЛУС» як інструмент психолінгвістики. Psycholinguistics. 2021. № 29 (2). C. 76-102. doi: 10.31470/2309-1797-2021-29-2-76-102.

5. Інформація до проєкту (для подальшої публікаціï) «Корпусно-експериментальна діагностика резилентності представників різних лінгвокультур та розробка поведінкових моделей їх адаптації до кризових явищ». URL: https:// knlu.edu.ua/ru/research/naukovo-doslidni-temi/ proekti-molodikh-vchenikh

6. Комар О.С. Досвід експериментального дослідження асоціативного сприймання національ- 
но-маркованих мовних одиниць. Когнітологія в системі гуманітарних наук : зб. наук. праць. 2014. C. 60-68.

7. Мартінек С. Емпіричні й експериментальні методи у сучасній когнітивній лінгвістиці. Вісник Львівського університету. Серія філологічна. 2011. № 52. С. 25-32.

8. Основні теоретико-методичні напрями психотерапіï. URL: https://pi.kubg.edu.ua/ images/stories/Departaments/idpmo/Kaf_ncix/ HaB4aJIHa/12_pcix_terap.pdf

9. Психолингвистика и лексикография : сб. научных трудов / Науч. ред. А.В. Рудакова. Воронеж : Истоки, 2016. Вып. 3. 245 с.

10. Стефанова Н.О. Етносеміометрична параметризація аксіоконцептосфер у британській та українській лінгвокультурах : дис. ... док. філол. наук : 10.02.17, 10.02.21. Київ, 2020. $564 \mathrm{c}$.

11. Анкета. Електронна версія «Великої украӥнської енииклопедіï». URL: https://vue.gov.ua/\% D0\%90\%D0\%BD\%D0\%BA\%D0\%B5\%D1\%82 $\% \mathrm{D} 0 \% \mathrm{~B} 0$.

12. Bellak L. Free Association: Conceptual and Clinical Aspects. International Journal of Psychoanalysis. 1961. № 42. C. 9-20.

13. Bion W. Transformations: Passage de l'apprentissage à la croissance (2002 Edn). Paris : PUF, 1965.

14. Hopkins J. Free energy and virtual reality in neuroscience and psychoanalysis: A complexity theory of dreaming and mental disorder. Front. Psychol. 2016. № 7. DOI: 10.3389/ fpsyg.2016.00922.

15. Joffe H., Elsey J. Free Association in Psychology and the Grid Elaboration Method. Review of General Psychology. 2014. № 18. P. 173-185. doi: $10.1037 / g p r 0000014173$.

16. Kapranov Y., Cherkhava O., Gromova V., Reshetnyk O. Methodological procedure of diagnosing behavioural stereotypes resilience of different language cultures representatives. Amazonia Investiga. 2021. № 10(39). P. 186-193.

17. Kehyayan A., Best K., Schmeing J.-B., Axmacher N., Kessler, H. Neural activity during free association to conflict-related sentences. Frontiers in Human Neuroscience. 2013. № 7. doi: 10.3389/fnhum.2013.00705.

18. Questionnaire Design For Needs Assessments In Humanitarian Emergencies. ACAPS. URL: https://www.acaps.org/questionnaire-designneeds-assessments-humanitarian-emergencies.

19. Rabeyron T., Massicotte C. Entropy, Free Energy, and Symbolization: Free Association at the Intersection of Psychoanalysis and Neuroscience. Frontiers in Psychology. 2020. № 11. DOI: 10.3389/fpsyg.2020.00366.

\section{REFERENCES}

1. Vygovskaya, D.G. (2014). Association experiment as one of the methods in psycholinguistics [Assotsiativnyy eksperiment kak odin iz metodov v psikholingvistike]. Nauka YuUrGU: Proceedings of the 66th Scientific Conference. Social and Humanitarian Sciences Section, 1157-1164.

2. Goroshko, E.I. (2005). Problems of conducting a free associative experiment [Problemy provedeniya svobodnogo assotsiativnogo eksperimenta]. Izvestiya $V G P U$, 3, 53-61.

3. Hryshchuk, Yu.V. (2021). Discursive markers of personality resilience as manifestations of its adaptation to crisis phenomena [Dyskursyvni markery rezylentnosti osobystosti yak proiavy yii adaptatsii do kryzovykh yavyshch]. Ad orbem per linguas: Proceedings of the International Scientific and Practical Video Conference «The World of Values and Values in the World». Kyiv: Vydavnychyi tsentr KNLU, 75-77.

4. Zahorodnia, O. (2021). Web project "STIMULUS" as an instrument of psycholinguistics [Veb-proiekt "STYMULUS" yak instrument psykholinhvistyky]. Psycholinguistics, 29 (2), 76-102. DOI: 10.31470/2309-1797-2021-29-276-102.

5. Project information (for further publication) "Corpus and Experimental Diagnostics of Resilience of Different Language Cultures Representatives and Behavioural Models Development for Adaptation to Crisis Phenomena" [Informatsiia do proiektu (dlia podalshoi publikatsii) "Korpusno-eksperymentalna diahnostyka rezylentnosti predstavnykiv riznykh linhvokultur ta rozrobka povedinkovykh modelei yikh adaptatsii do kryzovykh yavyshch"]. URL: https://knlu.edu.ua/ru/research/naukovo-doslidni-temi/proekti-molodikh-vchenikh

6. Komar, O.S. (2014). Experience of experimental research of associative perception of nationally-marked language units [Dosvid eksperymentalnoho doslidzhennia asotsiatyvnoho spryimannia natsionalno-markovanykh movnykh odynyts]. Kohnitolohiia $v$ systemi humanitarnykh nauk: Collection of scientific works, 60-68.

7. Martinek, S. (2011). Empirical and experimental methods in modern cognitive linguistics [Empirychni y eksperymentalni metody u suchasnii kohnityvnii linhvistytsi]. Visnyk Lvivskoho universytetu. Seriia filolohichna, 52, 25-32.

8. The main theoretical and methodological areas of psychotherapy [Osnovni teoretyko-metodychni napriamy psykhoterapii]. URL: https://pi.kubg.edu.ua/ images/stories/Departaments/idpmo/Kaf_ncix/ HaB4aJIHa/12_pcix_terap.pdf

9. Psycholinguistics and Lexicography: Collection of Scientific Works (2016). A.V. Rudakova (Eds.). Voronezh : Istoki, 3. 
10. Stefanova, N. O. (2020). Ethnosemiometric parametrisation of axioconceptosphere in the British and Ukrainian linguocultures [Etnosemiometrychna parametryzatsiia aksiokontseptosfer $\mathrm{u}$ brytanskii ta ukrainskii linhvokulturakh]: Thesis for a Doctoral Degree in Philology: Specialty 10.02.17, 10.02.21. Kyiv.

11. Questionnaire [Anketa]. Electronic version of the "Great Ukrainian Encyclopedia». URL: https:// vue.gov.ua/\%D0\%90\%D0\%BD\%D0\%BA $\% \mathrm{D} 0 \%$ B5\%D1\%82\%D0\%B0

12. Bellak, L. (1961). Free Association: Conceptual and Clinical Aspects. International Journal of Psychoanalysis, 42, 9-20.

13. Bion, W. (1965). Transformations: Passage de l'apprentissage à la croissance (2002 Edn). Paris: PUF.

14. Hopkins, J. (2016). Free energy and virtual reality in neuroscience and psychoanalysis: A complexity theory of dreaming and mental disorder. Front. Psychol., 7. DOI: 10.3389/fpsyg.2016.00922

15. Joffe, H., \& Elsey, J. (2014). Free Association in Psychology and the Grid Elaboration Method.
Review of General Psychology, 18. 173-185. doi: 10.1037/gpr0000014173.

16. Kapranov, Y., Cherkhava, O., Gromova, V., \& Reshetnyk, O. (2021). Methodological procedure of diagnosing behavioural stereotypes resilience of different language cultures representatives. Amazonia Investiga, 10(39), 186-193.

17. Kehyayan, A., Best, K., Schmeing, J.-B., Axmacher, N., \& Kessler, H. (2013). Neural activity during free association to conflict-related sentences. Frontiers in Human Neuroscience, 7. DOI: 10.3389/ fnhum.2013.00705.

18. Questionnaire Design For Needs Assessments In Humanitarian Emergencies. ACAPS. URL: https://www.acaps.org/questionnaire-design-needsassessments-humanitarian-emergencies

19. Rabeyron, T., \& Massicotte, C. (2020). Entropy, Free Energy, and Symbolization: Free Association at the Intersection of Psychoanalysis and Neuroscience. Frontiers in Psychology, 11. DOI: 10.3389/fpsyg.2020.00366. 